Article

\title{
Sonar for Environmental Monitoring: Construction of a Multifunctional Active Acoustic Platform Applied for Marine Renewables
}

\author{
Francisco Francisco ${ }^{1 *}$, Jan Sundberg ${ }^{1}$ \\ 1 Division of Electricity, Uppsala University, Box 534, 75121 Uppsala - Sweden \\ * francisco.francisco@angstrom.uu.se; Tel.: +46-184-715-909
}

\begin{abstract}
Marine renewable energy is emerging as one of the fast-growing industry in the last decades, as modern society pushes for technologies that can convert energy contained from winds, waves, tides and stream flows. The implementation of renewable energy technologies impose high demands on both structural and environmental engineering, as the energy converters have to work under extreme conditions where parameters such as sea-bottom configuration, water transparency and depth, sea-states and prevailing winds are harsh. Constant monitoring of the marine environment is crucial in order to keep this sector reliable. Active acoustics is becoming a standard tool to collect multi-dimensional data from physical, geological and biological properties of the marine environment. The Div. of Electricity of Uppsala University have been developing an environmental monitoring platform based on sonar systems. This platform aims to monitor the installation, operation and decommissioning of marine renewable energy converters. The focus will be given the observations of behaviors of marine animals in vicinity of energy converters but also structural inspection and monitoring of MRETs. This paper describes how this multifunctional environmental monitoring platform come to existence from the design to the deployment phase.
\end{abstract}

Keywords: Active acoustics; Multi Beam Sonar; Dual-beam Sonar; Environmental monitoring; Offshore renewable energy.

\section{Introduction}

The global growth is pushing energy technologies to new frontiers. Both renewable and nonrenewable energy sectors are exploring more and more resources within the marine environment. Explorations in marine environments take place where the physical conditions may harsh. Challenging sea-bottom configurations, deep and murky waters, high seas and strong winds are the common conditions that offshore industry faces today. Environmental data is crucial when planning and executing marine exploration, and the use of integrated monitoring platforms is becoming standard procedures in pre and post construction. However, the increase in industrial marine exploration brings the need to adopt alternative methods and tools that can provide better environmental data. Today, active acoustics (sonar systems) are an essential tool used to gather data of physical, geological and biological properties of the marine environment. Such systems together with passive acoustic instruments can provide a multi-dimensional information on the marine environment surrounding marine renewable energy technologies (MRETs) and other submerged structures.

In nature, the propagation of acoustic energy (sound) is used by marine animals to communicate, navigate and find food [1-2]. Sound is also used by humans as one of the most advanced mean of underwater remote sensing and subsea operations such as search and rescue, hydrocarbon exploration, harbors security, structures and diver inspections, operational oceanography and geophysics, military, among others. Within the marine renewable energy sector, active acoustics systems may become a key method to monitor MRETs, especially in murky and deep waters where divers and conventional methods are risky thus expensive. The use of imaging sonar (Sound 
Navigation And Raging) systems with higher operating frequency and resolution enables engineers and scientists to gather detailed information of the underwater marine environment in a similar perspective as is provided by optical and electromagnetic monitoring devices such as cameras and RADARs (RAdio Detection And Ranging) [1-2]. Such devices are able to provide both backscatter (acoustic) images as well as bathymetric maps of the surveyed area.

Sonar is an echo-ranging technology that uses acoustic energy to locate and survey objects within a water column [3,4]. Sonar systems are divided in passive or active types. The passive sonar listen for incoming sounds emitted from any specific object or background. Active sonar emits pulses of sound and listens for echoes. The basic elements of a sonar are a transducer, a multichannel receiver, and a display. A transducer converts over a controlled condition an electrical energy into acoustic energy propagating through the water and vice versa [5,3]. A set of multichannel receiver and a computer controls the excitation of the transducer and reception of echoes, the amplifications, the data processing, and the display unit. The display unit deliver an echogram for an echo sounder, or an echo-image (acoustic image) for a high-frequency imaging sonar. A typical echogram consists of a series of echo records in which each record represents the real time receiver output signal, visual encoded by intensity or color [6-8]. Echo-image consists of several echo records resulting from multiple beams that are spatially distinct, and the echo magnitude on each beam is generally encoded by intensity or color as in an echogram [3].

Sonar systems such as a multibeam (MBS), dual-beam (DBS), split-beam (SBS) among other categories, can provide qualitative information such as size, position, velocity and composition of targets within the water column. Putting together in a common platform, a MBS, DBS, and SBS can provide high-resolution environmental data of the space within hydrokinetic sites. Given the huge potential and energy density contained in marine renewable energy sources, MRETs in near future may compete with conventional energy systems without causing colossal damages to the environment [9]. Yet, there are environmental concerns arising from the potential hazard to marine organisms, which wave energy converter (WECs) and tidal energy converters (TECs) may cause [1011]. The use of acoustic instruments for marine remote sensing of hydrokinetic sites is already in use by few entities within the marine renewable energy sector. E.g. [11,12] used sonar systems to monitor fish and mammal interaction with tidal turbines and wave energy converters; [11-13] used multibeam sonar systems to map seabed within hydrokinetic sites. The FORCE project in the Bay of Fundy is a good example for highlighting the relevance of using active acoustics for environmental assessments surveys and continuous monitoring of hydrokinetics sites. In the FORCE project, the test site was monitored using multibeam sonar, side scan sonar, and deep-towed seismic systems, among other acoustic water column and seabed profilers [13]. The European Marine Energy Centre LTD (EMEC) has recently deployed its own integrated monitoring platform (IMP). This platform is on the seabed and is linked to land via a submarine cable [14]. Apart from these deployed projects, there is the FLOw, Water column and Benthic ECology 4-D (FLOWBEC-4D), which is an upward looking sonar platform designed to monitor marine animals within a designated water column [12]. It is selfcontained, portable but with a very limited survey span.

The Div. of Electricity, Uppsala University, is developing a multifunctional environmental monitoring platform, the UU Environmental monitoring platform (UU platform), illustrated in Figure 1. So far, this includes an autonomous system comprising MBS, SBS, DBS, and optical camera systems. The UU platform complements other environmental studies, which used other monitoring methods such as hydrophones, video cameras (e.g. [3]), and quantitative sampling (e.g. [4]). The vision is to minimize the risks associated with subsea work by means of monitoring the installation, operation and maintenance of MRETs. The UU platform aims to monitor marine organisms (with focus on mammals), inspect MRETs and other underwater structures, and perform seabed inspection among other water column measurements. This paper, describes the building process of the UU environmental monitoring platform. 


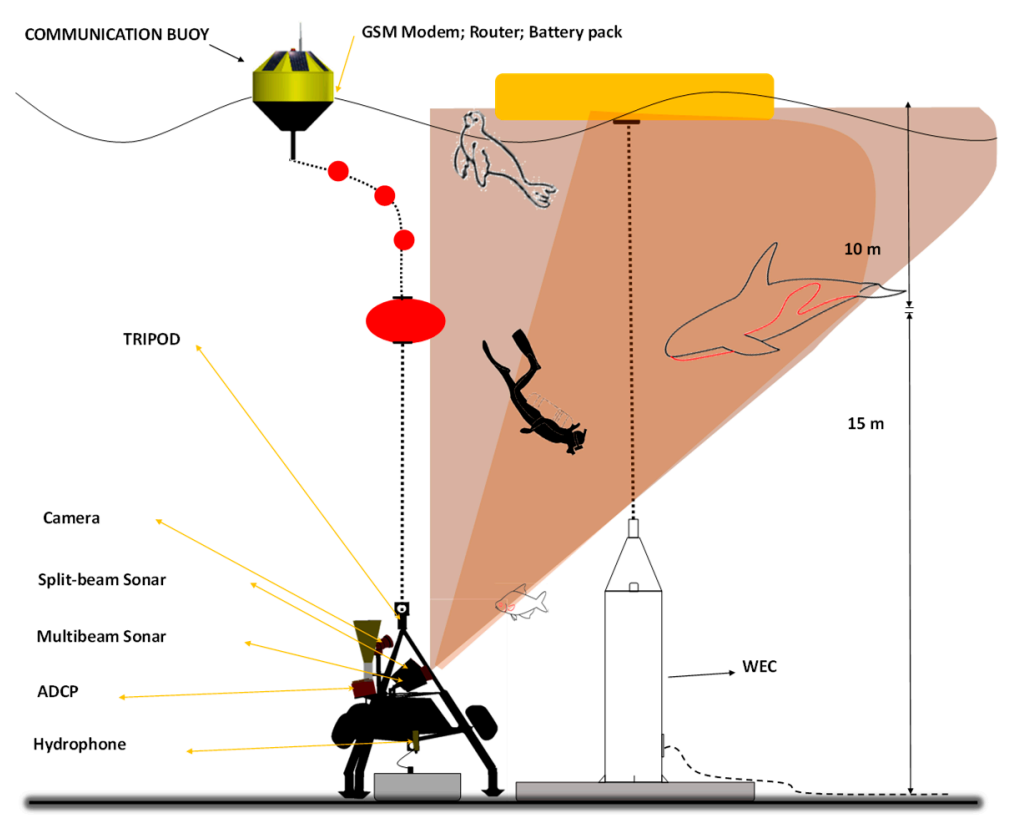

Figure 1. Illustration of the proposed environmental monitoring platform applied for marine renewable energy technologies. It comprises a tripod anchored to the seabed near an ORET. A submerged damping buoy is connected to a communication buoy. The DBS may be point

\subsection{Overview of sonar technology in use on UU monitoring platform}

Sound is an important guiding sense for marine animals such as dolphins, whales, seals, and fish [14 17]. Depending on the species, marine animals have a broad band of frequencies that cover frequencies from 0.01 to $200 \mathrm{kHz}[1-4,17]$. Therefore, anthropogenic noise with broadband frequencies from $0.01 \mathrm{kHz}$ up to above $2 \mathrm{GHz}$ may disturb the marine environment. Some of the animals change their behavior when the sonar is active, mostly in a way of leaving the surroundings (e.g. [18]). Death and injury of marine animals can also occurs during military exercises where powerful sonar systems are deployed. Thus the UU monitoring platform, uses sonar systems operating in frequencies above $200 \mathrm{kHz}$ at source level below $100 \mathrm{~dB}$ re $1 \mu \mathrm{Pa}$ at $1 \mathrm{~m}$, making the sonar surveys little harmful to the majority of marine life.

\subsubsection{The Multibeam sonar system (MBS)}

In a MBS, acoustic energy is irradiated and received in multiple angles across-track swath, typically in a fan shape $[18,19]$. Transmitting and receiving elements are arranged in a 2-dimensiconal array. Generally, each element transmits pulses (signals) individually in a crescent order, and the echo is received simultaneously by all receivers. However, each echo is processed separately enabling a number of echo-beams to be formed by combining the outputs of the several arrays of transducing elements with different phasing functions. This setup effectively steers the beam in several directions at the same time. Furthermore, these elements are arranged in a spiral configuration so that the beam pattern fill the field of view (FOV). Higher resolutions are even higher when the beams are aligned side by side in the same plane [19]. The number of beams can reach up to 1500 unities in angular sectors up to $180^{\circ}$ of FOV. Modern MBS systems can operate in frequencies up to $3 \mathrm{MHz}$ obtaining range resolution up to $1 \mathrm{~cm}$ and beam spacing of about $0.2^{\circ}$. The use of several narrow beams with a minimized transmit pulse (beam spacing) maximizes the effective sampling volume covered in the entire swath in a single ping. 
The setbacks of multibeam imaging sonar systems are mainly the range, which is limited to less than $100 \mathrm{~m}$ to no more than $10 \mathrm{~m}$ when the operating frequency is order of MHz. Noise is other big disadvantage of MBS systems. Background noise generated by seabed echoes affects the signal, mainly when the target is located at longer distance than the bottom depth [20-22]. Bubbles within the swath causes intense noise, mainly in sonar systems operating with very high frequencies. Data processing of a MBS sonar is complex and time consuming. Constant correction on pitch and roll are required, and MBS systems generates large volume of data.

\subsubsection{The Dual beam sonar system (DBS)}

In DSBs, the transducer is composed by two arrays of single frequencies elements, narrow and wide beam receivers. This configuration allows all the transducer elements to act equally in transmission producing a single narrower beam. However, the echo is received simultaneously by the two arrays of narrow and wide beams. The resulting effect is a coaxial beam pattern featuring a core beam within a relatively broad beam. The beam pattern can be pre-determinate by comparing the two output signals if a single target is detected [23-24]. This procedure allows the direct measurement of backscattering cross section by removing the beam pattern. DBS systems only make use of acoustic intensity or amplitude, taking no account to the phase of the signal. Thus, among the three parameters of the spherical coordinate system $(r, \theta, \varnothing)$, it can only determine two [25,24]. Dual beam sonar systems operates with frequencies up to $1 \mathrm{MHz}$, with a beam width up to $60^{\circ}$.

\subsubsection{The Split beam sonar system (SBS)}

The transducer in a split-beam sonar is divided into four quadrants, which transmit acoustic waves simultaneously, but receive the echoes independently, forming four beams arranged perpendicularly two by two. SBS systems uses both amplitude and phase of the acoustic signal to determine the accurate target position in a $r, \theta, \emptyset$ spherical coordinates taking advantage of the interferometer technique that uses phase differences between adjacent quadrants [26]. This type of sonar can operate in frequencies up to $1 \mathrm{MHz}$. In shallow waters, the sonar ping rate can be set very high to provide multiple reflections from a single target in order to facilitate tracking. Each target detection passes through a tracking-routine that combines successive pings in the same range cells into a track of the target path through the beam of the sonar [26,27]. SBS systems are superior comparing to DBS systems mainly due to superior SGN (signal to noise ratio) figures and accurate target location. However, target identification and spatial resolution can be limited [25].

\section{Mechanical design and installation of UU monitoring platform}

The platform may be divided into a submerged and a surface unity. The submerged unity includes a tripod and the surface unity includes a communication buoy (Figure 2). A mooring wire links the communication buoy on the water surface and a tripod anchored on seabed. The platform also includes a portable mount system mostly used for surface surveys and calibration tests. This platform was designed to operate manually, autonomously as well as remotely controlled.

\subsection{The submerged unity}

The submerged unity comprises a tripod made of aluminium and steel. This unity measures $1.7 \mathrm{~m}$ high, $1.8 \mathrm{~m}$ wide, and have gross weight of $250 \mathrm{~kg}$ (Figure 2a). Devices so far allocated to the tripod are one MBS, one DBS, one SBS, two video cameras (VC), one on-board computer and battery pack. The MBS is used to acquire acoustic images at near-field range up to $100 \mathrm{~m}$. The SBS and DBS are 
utilised to detect and track targets at longer range and provide a tri-dimensional information of the target position. The on-board computer is confined in the same waterproof box containing the batteries which are attached to the tripod. This computer controls all the devices, stores the data and run the control routines. The battery pack, housed in a waterproof box, comprises a set of four 130 $\mathrm{Ah} 12 \mathrm{~V}$ deep cycle batteries. These batteries are meant to supply power for the entire system for periods up to $80 \mathrm{~h}$, following a power-efficient plan, and could be charged by a set of solar panels placed on the communication buoy. Technical specifications of all devices allocated to the platform can be found in Table 1 .

\subsection{Portable mount system}

Portable mount system consist of a pole mount with an adjustable length of 1-5 m (Figure $2 b$ ). The pole mount is a lightweight pole (approximately $3 \mathrm{~kg}$ ) made of polyvinyl chloride reinforced with an aluminum stripe that is attached to a thin baseplate. The thin baseplate supports the sampling devices and act as a stabilizer. This portable munt system can be easily deployed from a surface platform.

\subsection{Communication buoy}

The buoy measures approximately $1 \mathrm{~m}$ of diameter, 1.7 of height and weights approximately $500 \mathrm{~kg}$ (Figure 2c). It will contain a set of solar panels, a modem, a router and a battery pack. This unity will establish the remote connection between the tripod and the users. It comprises a set of solar panels, a modem, a router and a battery pack. The buoy establish the remote connection between the tripod and the users. Data stored on the computer located on the tripod, is transmitted to the buoy by wire, and then uploaded to the users via wireless connection. Solar panels attached to the communication buoy charges both set of batteries located on surface and batteries located on the tripod. The buoy will use its own anchor and then linked to the submerged unity via umbilical cord.
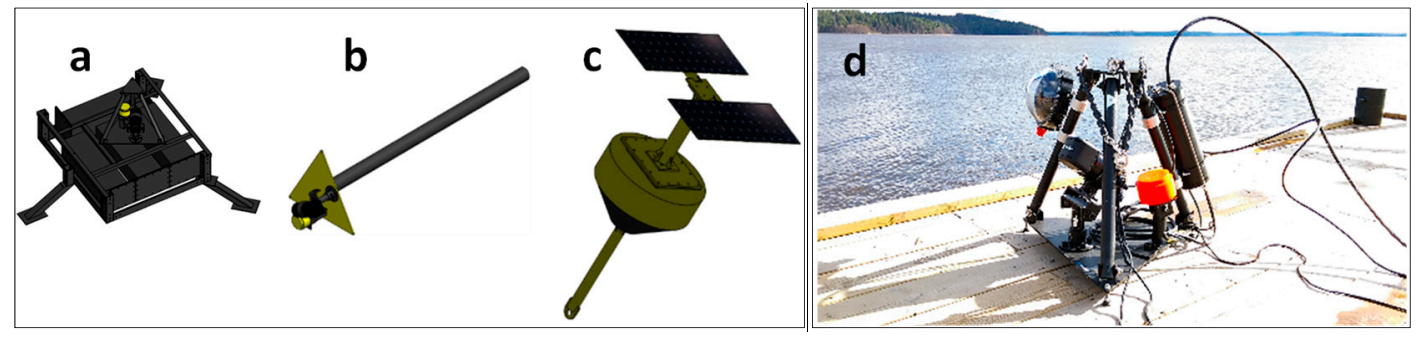

Figure 2. Computer rendering of a UU environmental monitoring platform. (b) An actual and redesigned concept of the submerged unit, aimed to save construction time and costs. (b) A portable pole mount used for surface surveys; (c) A communication buoy. (d) The actual top side of the tripod (submerged unit) equipped with a MBS, SBS and VC system. Image acquired prior to a real-conditions tests for system integration. Fyrisån river-mouth, Uppsala April 2016.

Table 1. Technical specifications of the main sensors so far integrated to the UU platform

\begin{tabular}{l|l}
\hline Component & Specification \\
\hline PC & Clock: 1.0 GHz \\
& RAM: 4GB DDR3 \\
& HDD: 2TB (storage memory) \\
& VGA: FULL HD 3D \\
& Input Voltage: 12 VDC \\
\hline MBS & Frequency: 0.9 MHz (operational)
\end{tabular}




\begin{tabular}{|c|c|}
\hline & $\begin{array}{l}\text { Number of Beams: } 768 \\
\text { fps: } 20 \mathrm{~Hz} \text { (sample frequency) } \\
\text { FOV: } 130 x 20 \text { (field of view) } \\
\text { Angular resolution: } 0.18^{\circ} \\
\text { Range resolution: } 2.54 \mathrm{~cm} \\
\text { Maximum range: } 100 \mathrm{~m} \\
\text { Input Voltage: } 12-48 \mathrm{VDC} \\
\text { Power consumption: } 13 \mathrm{~W}\end{array}$ \\
\hline DBS & $\begin{array}{l}\text { Frequency: 50/200 KHz (operational) } \\
\text { Number of Beams: } 2 \\
\text { FOV: } 29 / 12 \\
\text { Maximum range: } 762 \mathrm{~m} \\
\text { Input Voltage: } 10-19 \mathrm{VDC}\end{array}$ \\
\hline SBS & $\begin{array}{l}\text { Frequency: } 200 \mathrm{KHz} \text { (operational) } \\
\text { Number of Beams: } 4 \\
\text { FOV: wide- } 12 \\
\text { Maximum range: } 550 \mathrm{~m} \\
\text { Input Voltage: } 12-48 \mathrm{VDC}\end{array}$ \\
\hline VC 1 & $\begin{array}{l}\text { FOV: Hemispherical (180 ) } \\
\text { Sensitivity: 0,05 lux } \\
\text { Max. image resolution: } 2048 \times 1536 \\
\text { (3MP) } \\
\text { Max frame rate: (M-JPEVGA: } 22 \mathrm{fps} \\
\text { Video stream: (MxPEG) } 30 \mathrm{fps}\end{array}$ \\
\hline VC 2 & $\begin{array}{l}\text { Lense: } 2.8-8 \mathrm{~mm} / \mathrm{F} 1.2 \\
\text { FOV: } 92^{\circ}-32^{\circ} \\
\text { Sensitivity: } 0.04 \text { lux } \\
\text { Max. image resolution: } 2592 \times 1944 \text { ( } 5 \\
\text { MP) } \\
\text { Max frame rate (M-JPEG): } 30 \mathrm{fps} \\
\text { Video stream (MxPEG): H.264 }\end{array}$ \\
\hline
\end{tabular}

\subsection{System-integration plan}

The platform can be electrically divided into three sections: the sensors, the power supply and the communication unity (Figure 3). The sensors includes the already mentioned Multibeam sonar (MBS), Split-beam sonar (SBD), Dual-beam sonar (DBS), optical cameras (VC) and in near future a hydrophone (HYD). This sensor section also includes a network switch, controllers and an on board computer (PC). The controller works more as a power trigger which tells when each sensor should turn on/off. The power supply section consist of a battery bank, DC-AV inverters, and chargers. Devices that run with $12 \mathrm{~V}$-DC are directly connected to the battery bank, and the devices that need $110 / 220 \mathrm{~V}-\mathrm{AC}$ are connected to the battery through the inverters. The power chargers recharges the Battery Bank-I belonging to the submerged unity using power supplied by the Battery Bank-II located in the surface unity, or using external AC power supply from a land cable. The communication section comprises a Router, wideband GSM Antenna, a Battery Bank - II, a set of photovoltaic solar 
panels (PV), and a multipurpose Plug. The Router and the Antenna serve to establish a link via a wireless high-speed communication between the platform and the users remotely located. The Battery Bank - II serve to supply power to the router and antenna, also to recharge the batteries located in the submerged unity. The PVC recharge the Battery Bank - II. The multipurpose plug contains power and data connectors that are meant to stablish a direct wire-link between the submerged unity and a user when maintenance and is needed.

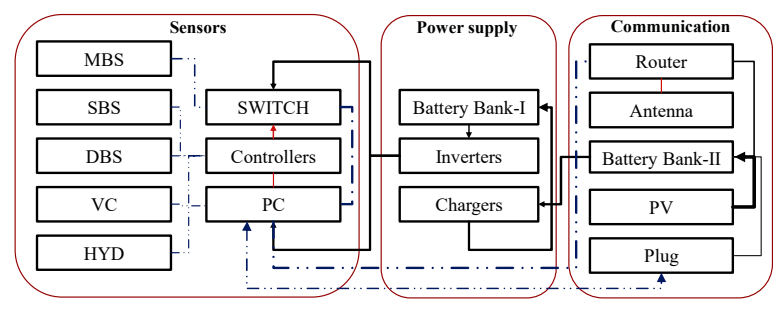

Figure 3. This diagram shows how the different sensors are linked to the power supply and communication systems. The dashed line represents data link, the full line represents the power supply.

\section{The data acquisition tool}

As aforementioned, an on-board computer controls all the devices allocated to the platform. Simple logic protocols supervises measurements taken by each device. To save memory and power, the sampling (measurements) occur in bursts. Each device samples in bursts of approximately 90-300 s, with intervals of 1800-7200 s. The number of samples per burst varies according to the device. A set of software is put together to process and analyze data. Data from each instrument is treated by its own algorithm and routine. An example given by Figure 4 describes how the MBS and DBS data is acquired processed and analyzed [15].

The MBS uses the BlueView sonar developing kit (SDK 3.6) and ProViwer4 software for data acquisition and processing. The data is acquired as a sequence of pings. Each ping comprises 768 beams that form an acoustic image. Each acoustic image contains information of backscatter intensity of insonified targets, water depth and distance to target, geo and velocity data. The resulting acoustic images will be analyzed using Visual Studio and Matlab, through a routine described in the Figure 4a.

The DBS (and the SBS) provide pre-processed data of acoustic backscatter intensity in relation to water depth and distance to target, in forms of echograms. Here the acoustic data has already timevaried-gain (TVG) compensation. Each ping also provides geo and 2-D velocity information of the targets, water and air temperature data. Echograms are further processed and analyzed using Matlab (Figure $4 \mathrm{~b}$ ). The remaining instruments such as VC have a rather simple procedure to process and analyze data. 


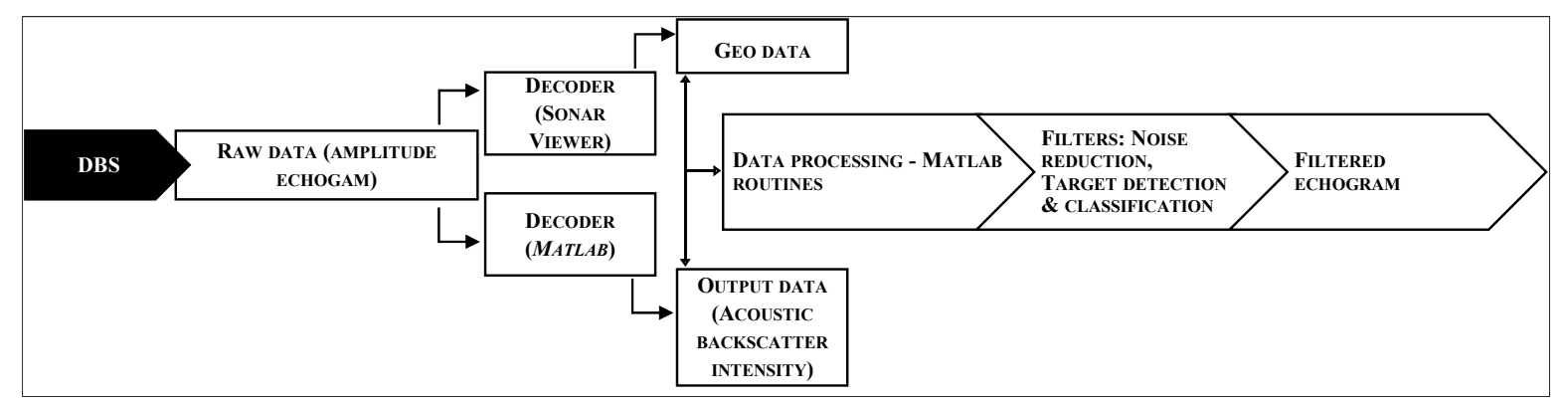

(a)

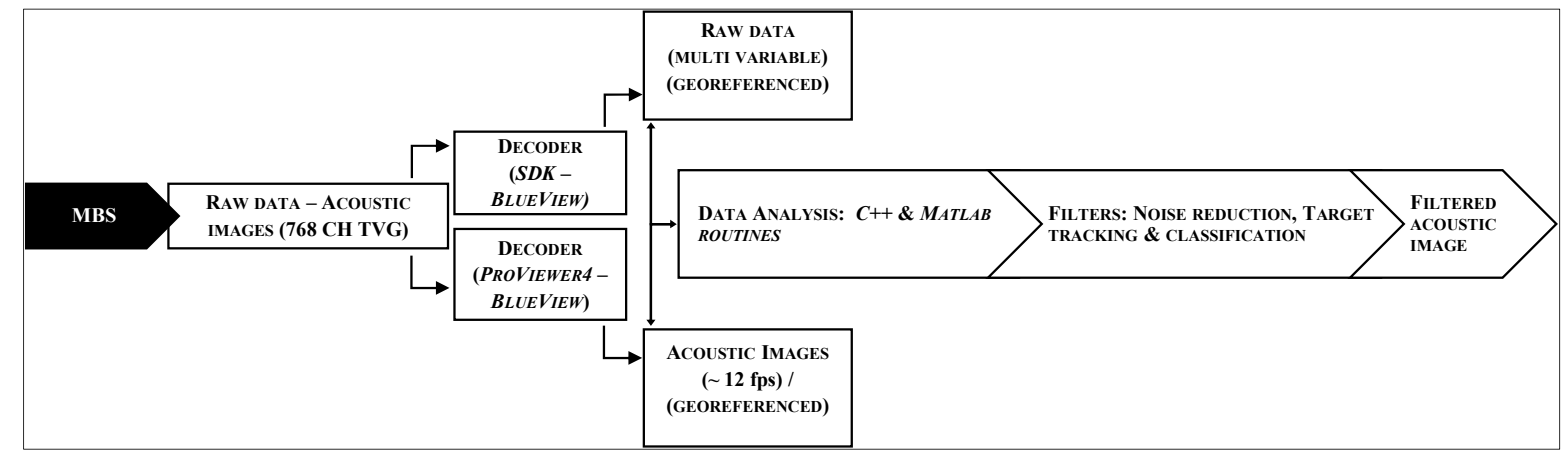

(b)

Figure 4. Overview of the data acquisition and processing (DAQ) architecture for detecting, tracking and classifying underwater targets of interest. The data is acquired by the sonar transducers, then pre-processed by sonar software. Algorithms (in developing phase) decode and further filter the acoustic signal. (a) The DBS data is relatively slow to process and analyze. It goes through three sets of algorithms to come out with a raw echogram. Then the raw echogram is filtered by another set of algorithms, and then georeferenced. (b) The MBS signal is quickly processed by the SDK/ProViwer software running on $\mathrm{C}++$ programming environment. The acoustic images are then analyzed and filtered using the same software previously mentioned, and using other image analyzing tools such as Matlab - Image processing Toolbox. [15]

\section{Deployment strategies}

Given the versatility of the monitoring platform, the entire system can be deployed in several configurations in accordance with the objective of the survey and physical water conditions. For surveys undertaken on board of a vessel with a down-looking setup the platform can be deployed using a pole mount attached to a vessel (configuration-A). The same configuration can be achieved by replacing a vessel by a fixed structure (configuration-B). For up-ward looking surveys, the platform utilize the tripod that can be either deployed temporary using an umbilical cord from a vessel (configuration-C) or from a fixed structure (configuration-D). For long-term surveys within hydrokinetic sites (configuration-E), the platform is deployable in an up-ward looking configuration, in which the tripod is anchored to the seabed and then linked to the surface buoy through an umbilical cord and a safety line. This configuration enabling an autonomous operation. This is the main idea of this project. The above-mentioned deployment strategies are illustrated in Figure 5. 

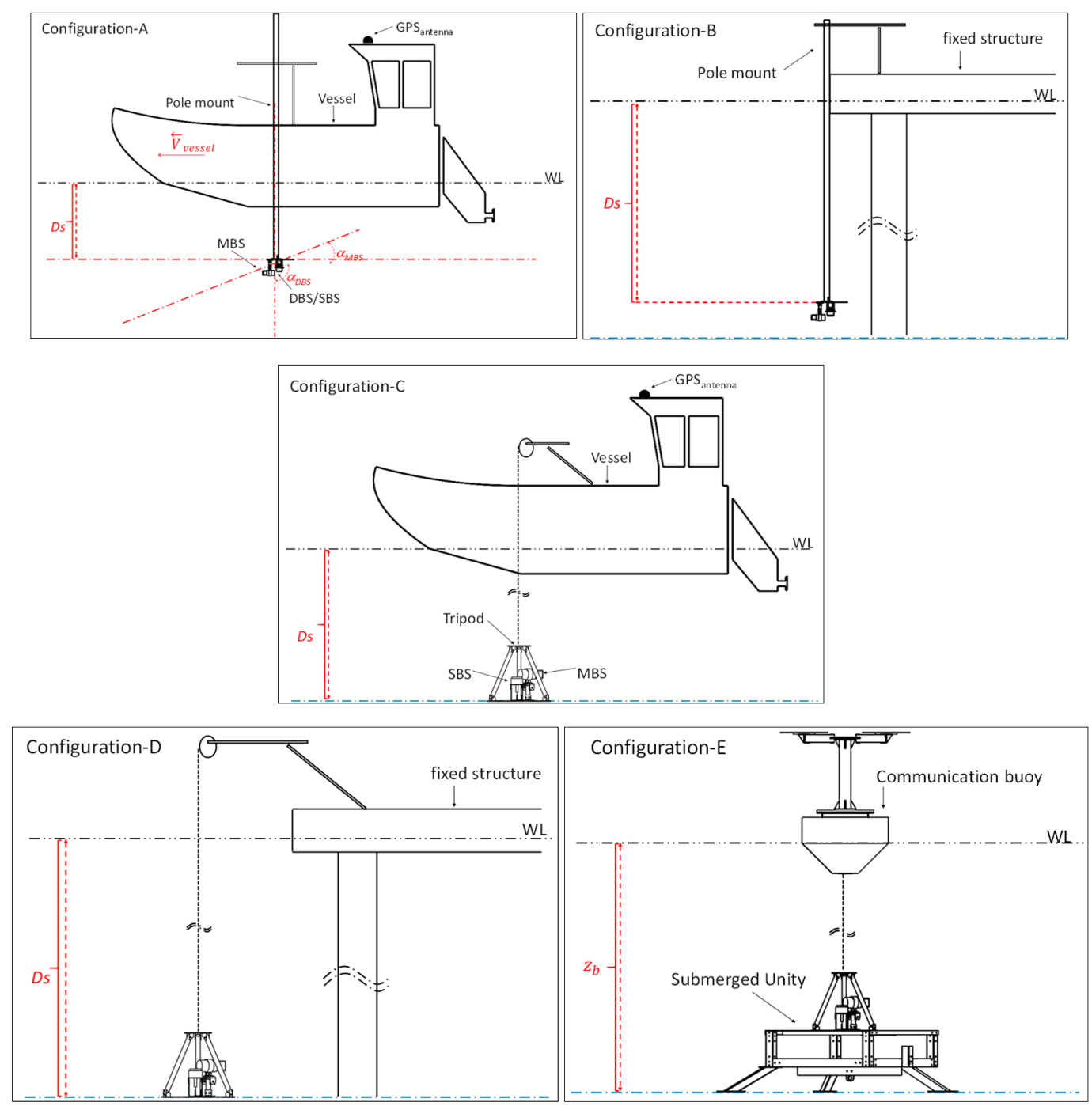

Figure 5. Illustration of different configuration in which the proposed platform can be deployed. (a) Polo mount deployed from a vessel (configuration-A). (b) Pole mount deployed from a fixed structure on shore (configuration-B). (c) Tripod deployed from a vessel (configuration-C). (d) Tripod deployed from fixed structure (configuration-D). (e) Full deployment of the entire monitoring platform for long term surveys (configuration-E). In surveys using deployment configuration-A and B the MBS were at three pitch angles $\left(\alpha_{\mathrm{MBS}}=0^{\circ} 45^{\circ} ; \alpha_{\mathrm{MBS}}=90^{\circ}\right)$. The DBS was always at fixed pitch angle of $\alpha_{\mathrm{DBS}}=90^{\circ}$. The vessel travels at a constant speed of $6 \mathrm{kmh}^{-1}$ or $9 \mathrm{kmh}^{-1}$ depending on the survey stage. Both sonar systems can be deployed in drafts (Ds) ranging from $0.1 \mathrm{~m}$ to $4.0 \mathrm{~m}$.

\section{The experimental setup for surface surveys using a portable mount system}

Most of the survey conducted until today were surface surveys using the pole mount system (configuration-A and B, illustrated in Figure 5 and Figure7). However, by the date that this article was written, the platform was deployed for long-term survey at Lysekil Wave Power Research Site (using configuration-E). For that reason, this paper will only focus on performance characteristics of the platform on surface surveys. Real-conditions tests were conducted in three different sites. Siteselection criteria included finding locations with distinct aquatic characteristics, these consisted of marine, fluvial-quasi-static and fluvial-highly-dynamic aquatic environments. Two of these test sites were also hydrokinetic sites, which means that there were MRETs deployed in place. The marine aquatic environment corresponds to the Lysekil Wave Power Project site (58ำ11.85N, 11⒉ $226 \mathrm{E})$ where a number of UU WECs have been deployed [29-31]. The fluvial-highly-dynamic aquatic 
environment corresponds to the Söderfors (Current Power) Project test site ( $\left.60^{\circ} 23.26 \mathrm{~N}, 17^{\circ} 14.90 \mathrm{E}\right)$, where a low-rotational speed vertical axis turbine is deployed. The fluvial-quasi-static aquatic environment corresponds a dock area by the Flottsund Bridge $\left(59.787434^{\circ} \mathrm{N}, 17.662059^{\circ} \mathrm{E}\right)$ located over the section of Fyrisån River that passes through Uppsala. More information of about the Lysekil Wave Power and Söderfors Project site can be found in [29-31].

Initial tests were conducted in calm and steady conditions such calm docks and harbors. There also was a need to address if the platform performance would be affected by bio-physical conditions such as turbidity, suspended particles, turbulence, stratification among others water properties. Hypothesis is that the water properties vary in time depending on several environmental factors, and this could affect the quality data acquired by sampling devices such as a MBS, SBS, DBS, and VC systems. Therefore, surveys were conducted in every season for a period of 18 months, covering all variety of weather conditions. Specific and well known targets were sampled, for shape, size and feature recognition. Sampled targets were the WECs, Söderfors turbine, and foundations pillars of Flottsund Bridge, hull of mid-size recreational vessels, divers and wild fish (free and trapped in test fishing nets). More about surface survey results can be found in $[15,16]$.

The outline-survey technique was the most used, split in two stages (Fig 6). In the first stage, the vessel quickly covered the overall site on widely spaced transepts (scouting transepts) to detect and locate targets. The vessel traveled at a steady speed $\left(\overleftarrow{V}_{\text {vessel }}\right)$ of $9 \mathrm{kmh}^{-1}$. In the second stage, the vessel returned to each target locations, and performed an intensive and detailed survey at steady speeds of approximately $6 \mathrm{kmh}^{-1}$.

The MBS and DBS systems were deployed in different drafts $(D s)$ that varied from $D s=0.1 \mathrm{~m}$ to $D s=$ $4.0 \mathrm{~m}$ (Fig 6). The MBS transducer head was deployed in three adjustable pitch angles (OMBS) in respect to the water level $(\mathrm{WL})$, these were $\alpha_{\mathrm{MBS}}=0^{\circ}, \alpha_{\mathrm{MBS}}=45^{\circ}$ and $\alpha_{\mathrm{MBS}}=90^{\circ}$ respectively. The DBS transducer head was always deployed with constant pitch angle of $\alpha_{D B S}=90^{\circ}$. Here, each survey employed a total sampling period of $60 \mathrm{~min}$, burst of $90 \mathrm{~s}$ and blank of 120 to $600 \mathrm{~s}$.

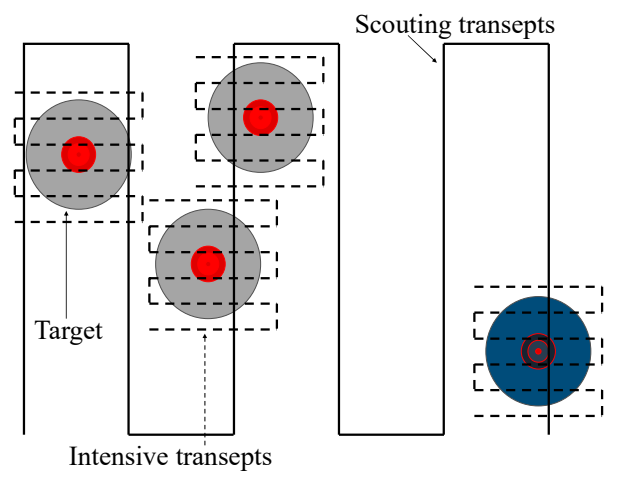

Figure 6. Illustration of two-stage survey tracks adopted to investigate isolated targets such as the UU WEC and the Söderfors turbine. The full line represents the scouting transepts which were wide and quickly travelled. The dashed lines represents the intensive and detailed observation of specific targets upon its location. 


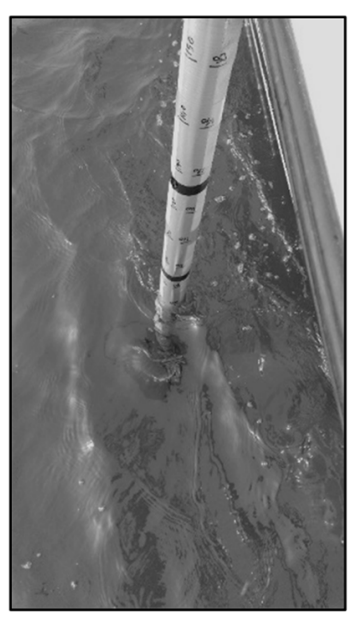

Figure 7. A pole mount system used for surface surveys (configuration-A). Here, a platform was equped with MBS, DBS and a VC systms on board of vessel.

Depth measurements were analysed using the algorithm shown in Eq. 1. This algorithm assumed that the pitch and roll errors are small or self-corrected by the sonar's computer thus, the module of real depth $(Z)$ can then be calculated takin in account the heavy, tide and draft of transducer as:

$$
Z=z_{\text {eco }} \pm z_{\text {heave }}-z_{\text {tide }}+z_{\text {draft }}
$$

Where $z_{\text {eco }}$ is depth value is measured by a DBS, $z_{\text {heave }}=2 \cdot \operatorname{std}\left(z_{\text {eco }}\right)$ is a sea wave height derivate by altimetry data measured by a GPS integrated to the sonar system, and $z_{t d e}$ is a tide height in synchrony with the insitu measurements and $z_{\text {draft }}$ is the transducer draft.

\section{Initial performance results}

\section{1 Inspection of MRETs}

Using deployment configuration-A and B, results show that the MBS performed well on detecting the UU WECs as well as the Söderfors Turbine. An echo-image of the Söderfors turbine is shown if Figure 8a. Given the narrow structure of the blades, most of the acoustic energy is scattered by the rocky seabed with a much higher acoustic reflectivity comparing to the turbine structure. However, it is much easier to the human eye to see a turbine when the images are presented in multi-frame as a movie. The fact that the acoustic retro-reflectivity from the rocky riverbed surpasses by a large magnitude the turbine's echo acoustic reflectivity may be due to the deployment configuration utilized in this case. The object shown on Figure 8a is an acoustic image of a UU WEC and the surrounding environment. The MBS head was approximately $18 \mathrm{~m}$ from the top of the WEC. The seabed and the WEC's cylindrical gravity foundation are the most reflective targets. The cylindrical body of the WEC its self is not the strongest acoustic target. The sound tends to scatter away from the transducer when it irradiates trough cylindrical and spherical surfaces, contrary occur with flat surfaces. The dark area behind a WEC represents the range limit of acoustic beams. These power unities were surveyed in several occasions under different environmental conditions. The survey referent to this acoustic image was conducted in October 2014. Similar images acquired during June, July and August 2015 were very noisy and distorted mostly due to water column stratification. The corresponding DBS echogram displays the returning acoustic energy reflected by the WEC structure. The MBS proved able to monitor maintenance work in WECs as Figure $8 \mathrm{c}$ shows a diver inspecting the top-end funnel of a UU WEC deployed at $25 \mathrm{~m}$ depth, the diver is head down at approximately 
$20 \mathrm{~m}$ of depth. The DBS system also detect WECs. An ecogram in Figure 8d shows two UU WECs, the arcs represents acoustic backscattering from the metal body, depending on the vessel speed, these arcs can become wide and spread (fast transepts) or dense with a more realistic WEC shape (quasistatic transept). Echograms form DBS provide with high accuracy a position in terms of depth, of every element detected, as an example, from the echogram in Figure 8d, was evident that from left to right, the WECs had $7.5 \mathrm{~m}$ and $6 \mathrm{~m}$ of height respectively. This feature is relevant to classify targets and to guide divers, vessels and under

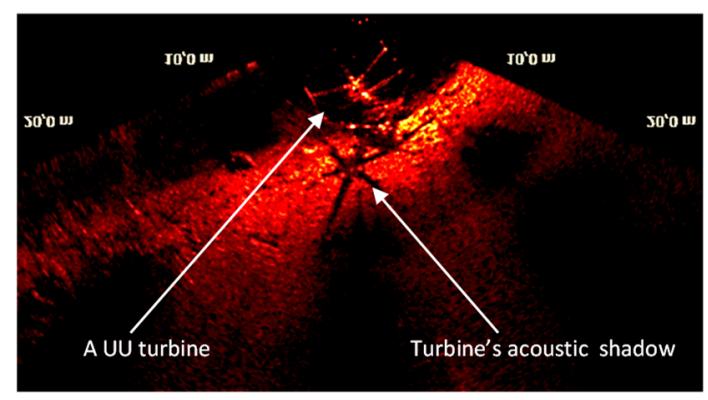

(a)

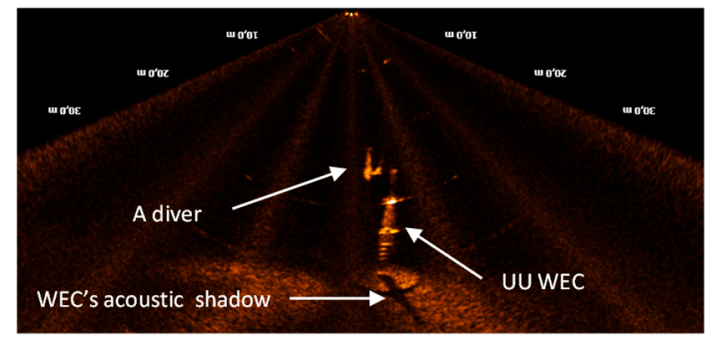

(c)

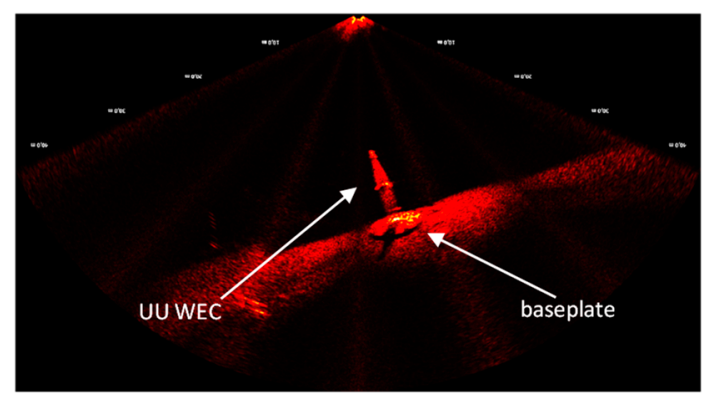

(b)

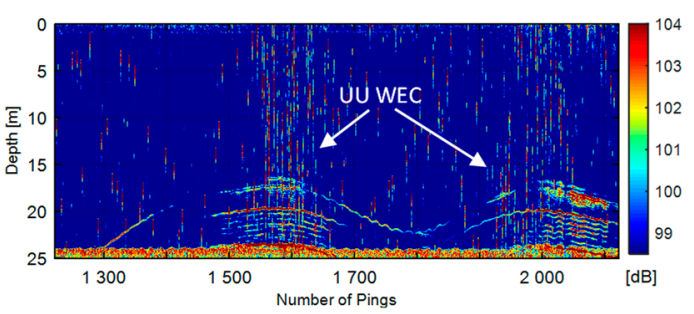

(d)

Figure 8. Acoustic image captured using a MBS system. (a) A Söderfors turbine, most of the acoustic energy is scattered by the rocky seabed with a much higher acoustic reflectivity comparing to the turbine structure; (b) The environment surrounding a UU WEC deployed at depth of $25 \mathrm{~m}$. The seabed and the WEC gravity foundation are the most reflective targets due to its higher density. The dark region represents the range limit of acoustic beams; (c) A diver inspecting a UU WEC; (d) A DBS echogram referent to WECs, the arcs represents acoustic backscattering from the metal body encapsulating the generators.

\subsection{Seabed inspection and depth measurements}

The MBS coupled with DBS delivered good seabed inspection results. A number of surveys were conducted to measure depth and access the seabed conditions prior to deployment of WECs. Seabed inspections were also conducted to evaluate water pathways for large deployment vessels that needed to dock in narrow and shallow harbors where WECs are loaded and unloaded. Figures 9 to 10 show the seabed at the dock of a wave power factory in Lysekil though an acoustic image captured with a MBS and the respective bottom-depth profile measured by a DBS. The survey performed several transversals (east-west) and longitudinal (south- north) transepts to gather bottom depth data. Figure 9a show a longitudinal bottom depth profile measured from the middle of the dock area where the depth varies from $4 \mathrm{~m}$ at the east side to $5.5 \mathrm{~m}$ in the west side. Figure $9 \mathrm{~b}$ show a transversal profile in which the depth measured $5 \mathrm{~m}$ by the dock towards the far open side, and increases towards the wide-open pathway to values of $9 \mathrm{~m}$ (Figure 9b). Figure 9c Show spatial contours referent to bathymetric contours derivate from eight transepts depth measurements done in which two of them are shown in Figure 9a-b. The seabed in this area is in average flat with a south-north (transversal) inclination east to west of approximately $2.3^{\circ}$ and a longitudinal inclination of approximately $2^{\circ}$. The 
MBS detected several wrecks with approximate sizes varying from 0.4 to $2.3 \mathrm{~m}^{2}$ as shown in Figure 10a-b. In Figure 9a, the wreck 1 and wreck 2 looked to be metallic barrels, while in Figure 9b, the wreck 3 looked to be a table upside down, a harbor wall made of metal can also be seen in Figure $9 \mathrm{~b}$. The seabed appears to be made by thin layer of soft subtract which would be lying under a hard bottom layer which is the general characteristics of the seabed on that region.

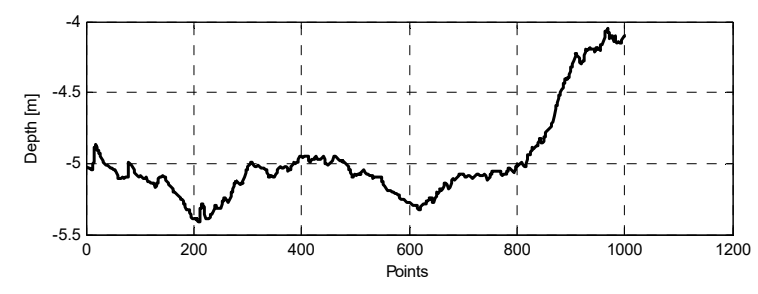

(a)

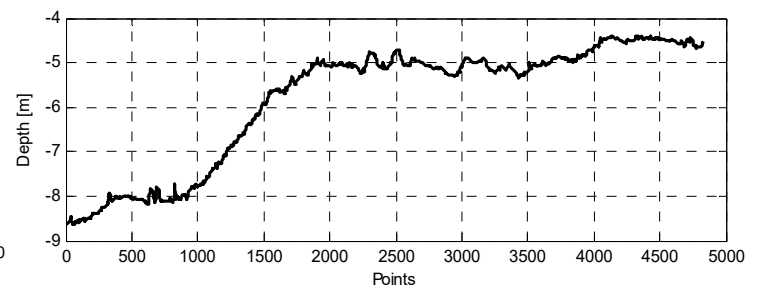

(b)

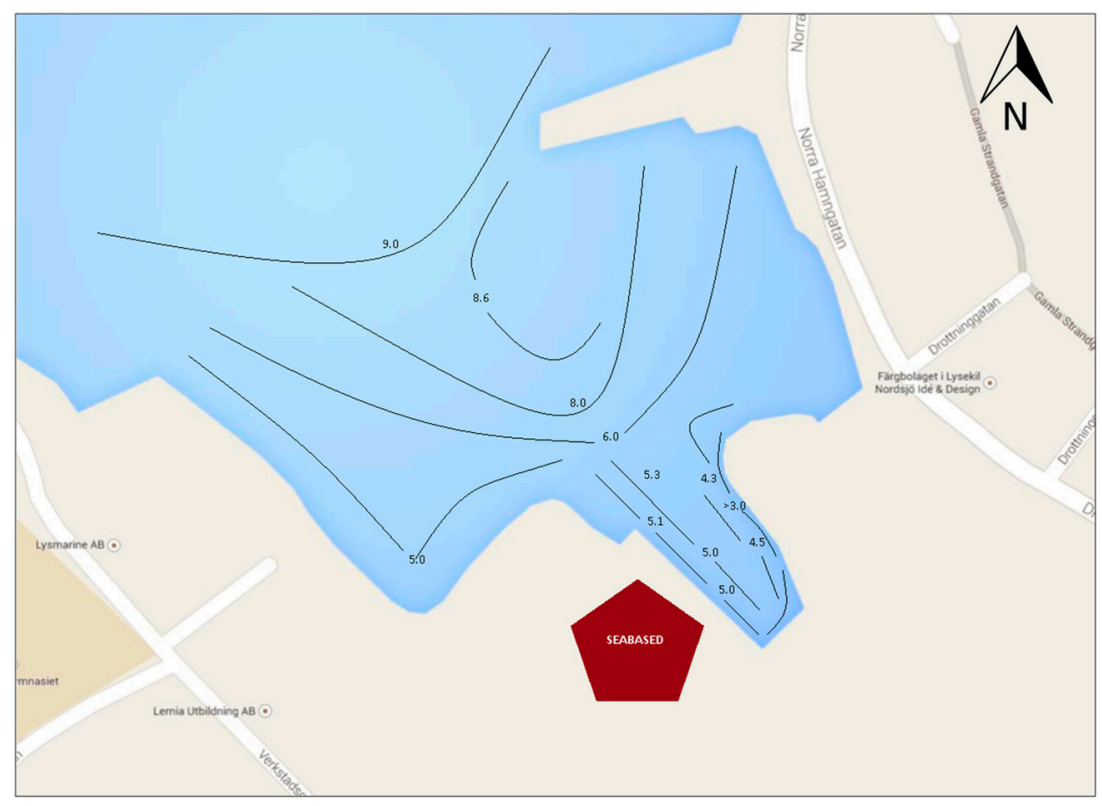

(c)

Figure 9. Results for a seabed inspection of the area by the dock a wave power factory (Seabased Industry AB) in Lysekil: (a) Measured depth [m] displayed in for an east to west longitudinal transect on the middle of surveyed area; (b) Measured depth in a south to north transversal transept in which the depth increases from the dock area towards the far open side; (c) Bird view at $20 \mathrm{~m}$ scale, of the surveyed area including the spatial contours of measured depth.

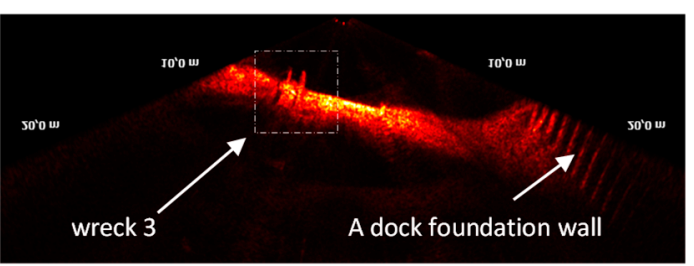

(a)

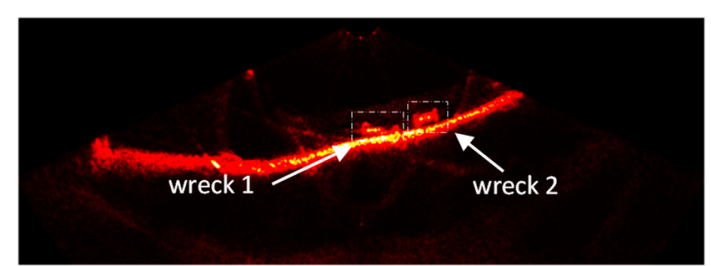

(b)

Figure 10. Overview of the seabed area by a wave power factory in Lysekil, through an imaging MBS system. Seabed inspection detected wrecks lying on the bottom. (a) Wreck 1 measured approximately $0.7 \times 0.6 \mathrm{~m}$, wreck 2 measured $0.8 \times 0.5 \mathrm{~m}$, and were detected in the south side of the dock area. (b) Wreck 3 measured $1.5 \times 1.5 \mathrm{~m}$, and was detected by the middle of the dock area few meters from the harbor wall that was made of steel with in a c-shape. 


\subsection{Echo intensity analysis}

Data analysis for target identification and classification can be improved by undertaking supervised and unsupervised classification of the acoustic backscattering intensity values. By undertaking an unsupervised classification in a set of acoustic backscattering data collected from a UU WEC (shown in Figure 8b) using MBS and DBS systems, it was possible to identify at least four clusters of data (Figure 11a). The first cluster is referent to echoes from the UU WEC (red dots), the second cluster represents the seabed, the third cluster represents the background noise and the surface turbulence, and the fourth cluster contains the most frequent echoes of the entire volume backscattering. These clusters are not exact, but they are representative.

It is also possible to improve target identification and classification by analysing echograms, histograms and clusters of the same soundings (Figure 11b). This method is useful for accessing the discrete distribution of acoustic backscattering intensity. Here, histograms were calculated using the data shown on the echogram of Figure 9d. This information can tell how detected targets of interest, background noise, benthic zone, and water surface contributes to the entire echo intensity detected by the sonar. Echo-intensity referent to targets had most frequent values between $-98 \mathrm{~dB}$ and $-102 \mathrm{~dB}$, the water surface and riverbed had values above $-100 \mathrm{~dB}$, suspended targets and noise had values between $-65 \mathrm{~dB}$ and $-96 \mathrm{~dB}$. The histogram of mode represents mainly the background noise and a less the UU WEC. The histogram of minimum represents almost all the low values of echo intensity within the sampled volume, and the histogram of maximum represents mainly the UU WEC and the seabed. These findings are ambiguous although this method needs more tuning and the results need further analysis, however, the potential is of this method is high.

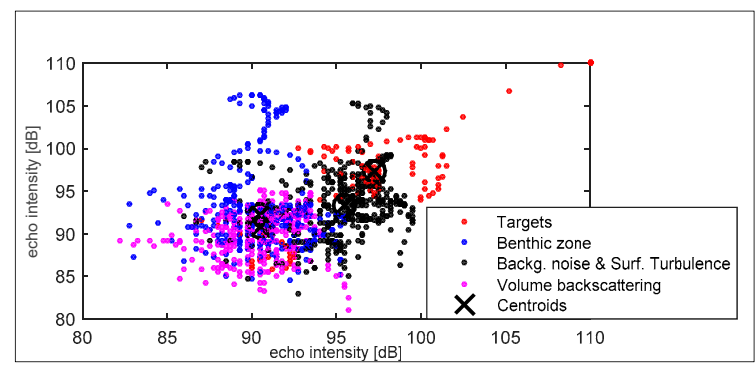

(a)

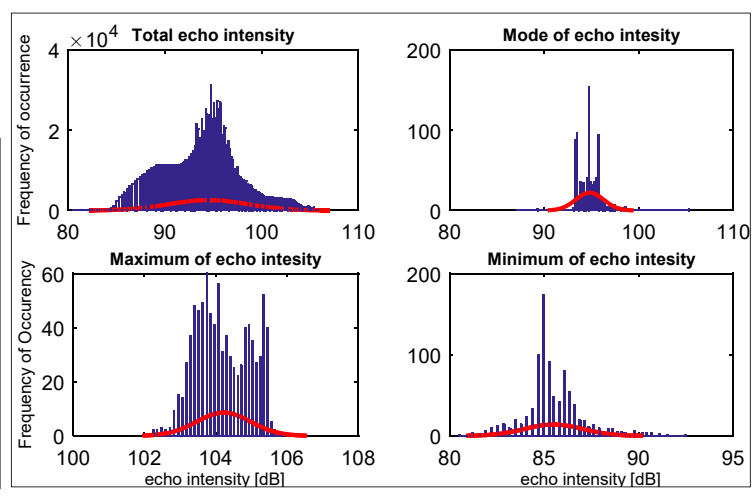

(b)

Figure 11. Post-analysis of echo intensity data referent to an echogram of a UU WEC. (a) k-means clustering that identified four groups of targets namely: red dots - UU WEC, blue dots - seabed, black dots - background noise and surface turbulence, cyan dots - entire volume backscattering of targets with low echo intensity. (b) Histogram showing the distribution of the total volume backscattering, the mode that represents background noise, the maximum that represents the target, and the minimum that represents both target and noise.

\section{Discussion}

Both the hardware and the software parts of this platform are still under development. The performance results shown in this paper are demonstrative. However, work still needs to be done to unlock the full potential in terms of data treatment and analysis. Additional sensors such as pitch and roll, pan and tilt and compass need to be integrated to the platform in order to improve data accuracy. 
To avoided noise due to Doppler shifts resulting from water current, moving debris etc, a proper sonar-head pitch angle and orientation needs to be calibrated carefully.

This paper provided an initial results from surveys carried out from the water surface, which means that only two of five deployment configurations carefully were analyzed. This means that sonar data from targets located on the benthic layers could be greatly affected by noise restrained within a water column, due to a longer ping duration. If this hypothesis is true, then a deployment configuration in which the platform is closer to the target (configurations C-D) can provide data with less noise. Furthermore, water column stratification also caused interferences and excessive noise to the sonar data acquired from the surface. The water layers of different density and temperature act as an acoustic buffer scattering the majority of the sound emitted by a sonar, making it difficult to detect targets located beyond the stratified layers.

It proved to be challenging to conduct bottom depth measurements using small vessels without dynamic positioning systems that maintain the platform in the wright path at the wright speed. However, the acquired bottom depth data could be used for operational purposes, as a set of quality control protocols are conducted during and after a survey.

In respect to interpretation of an acoustic images produced by a MBS system, it is preferable that a sonar operator has a pre-knowledge of what to expect in terms of target shape, size and orientation. Acoustic images are not always easy to extract features, first due to the fact that it is typically presented in 2-Dimensions, then due to the fact that noise and acoustic shadows can cause deformation to a real image.

\section{Conclusions}

The present work and the calibrations tests described in $[15,16]$ concluded that a selected MBS system could detect targets as small as $3 \mathrm{~cm}^{2}$ within a range shorter than $100 \mathrm{~m}$ or $3 / 4$ of this range. The MBS was also capable of resolving isolated targets located near high reflective objects such metal and concrete structures, as well as near the bottom and water surface. However, several factors such as water turbidity, suspended particles, water column stratification, turbulence, and air bubbles can drastically affect the quality of an acoustic image. The quality of a MBS acoustic image is also dependent on the deployment configuration and weather conditions. The DBS was able to detect with high accuracy, any target located at any position within the acoustic swath. However, the DBS data can be adversely affected by the bulk of suspended particles within the water column.

Contrary to the DBS, which only works at its best when deployed at pitch angles near $90^{\circ}$, the MBS in most of the cases produced better acoustic images when the transducer head was oriented at pitch angle of $45^{\circ}$. However, in shallow waters (depth $<10 \mathrm{~m}$ ) a pitch angle of $90^{\circ}$ was more desirable. When a target was located at depths near the MBS maximum range, a pitch angle of $0^{\circ}$ was better suitable.

Both MBS and DBS systems performed well on detecting UU WECs, Söderfors turbine, wrecks and other types of underwater structures located within $100 \mathrm{~m}$ from the head of sonar. These two sonar systems also produced high quality data of seabed inspection that could be used to access local bathymetry and bottom composition. Advanced post-processing techniques such as supervised and unsupervised classification methods can greatly increase the understanding of the sonar data. 
This work also concludes that sonar data in a form of acoustic images or ecograms or simply altimetry can provide a range of information such as bathymetry, biomass, structural inspections of underwater technologies and structures, magnitude and direction of cavitating flows, underwater navigation among other relevant information vital for deployment, operation and maintenance of MRETs.

\section{Acknowledgements}

This project has received funding from the European Union's Seventh Framework Programme for research, technological and demonstration under grant agreement no 607656. The authors also acknowledge.

\section{References}

1. Wahlberg, M.; Westerberg, H. Hearing in fish and their reactions to sounds from offshore wind farms. Mar. Ecol. Prog. Ser. 2005, 288, 295-309.

2. Rudstam, L. G.; Jech, J. M.; Parker-Stetter, S. L.; Horne, J. K.; Sullivan, P. J.; Mason, D. M. Fisheries Acoustics. Fisheries Techniques (Chapter 13). Am. Fish. Soc. 2013, 40.

3. Haikonen, K. Underwater radiated noise from Point Absorbing Wave Energy Converters; 2014.

4. Langhamer, O.; Haikonen, K.; Sundberg, J. Wave power-Sustainable energy or environmentally costly? A review with special emphasis on linear wave energy converters. Renew. Sustain. Energy Rev. 2010, 14 (4), 1329-1335.

5. Jefferson, T. A.; Leatherwood, S.; Webber, M. A.; United Nations Environment Programme.; Food and Agriculture Organization of the United Nations. Marine mammals of the world; United Nations Environment Programme, 1993.

6. Caruthers, J. W. Fundamental of Marine Acoustics. 1977, p 165.

7. Simmonds, J.; MacLennan, D. Fisheries acoustics: Theory and practice: Second edition; 2007.

8. Lurton, X. An introduction to underwater acoustics : principles and applications; Springer Verlag, published in association with Praxis Publishing, 2010.

9. Hammar, L.; Andersson, S.; Rosenberg, R. Adapting offshore wind power foundations to local environment Adapting offshore wind power foundations to local environment; 2010.

10. Hammar, L. Power from the Brave New Ocean: Marine Renewable Energy and Ecological Risks; 2014.

11. Wilson, B. Batty, R. S., Daunt, F. \& Carter, C. Collision risks between marine renewable energy devices and mammals, fish and diving birds. Water 2007, No. March, 1-110.

12. Williamson, B. J.; Blondel, P.; Armstrong, E.; Bell, P. S.; Hall, C.; Waggitt, J. J.; Scott, B. E. A Self-Contained Subsea Platform for Acoustic Monitoring of the Environment Around Marine Renewable Energy DevicesField Deployments at Wave and Tidal Energy Sites in Orkney, Scotland. IEEE J. Ocean. Eng. 2016, 41 (1), 67-81.

13. Environmental Assessment I Fundy Force http://fundyforce.ca/environment/enviromental-assesment/.

14. Marine Energy : EMEC: European Marine Energy Centre http://www.emec.org.uk/marine-energy/.

15. Francisco, F.; Sundberg, J. Sonar for environmental monitoring. Initial setup of an active acoustic platform. Proc. Int. Offshore Polar Eng. Conf. 2015, 2015-Janua, 1175-1179.

16. Francisco, F. G. A.; Sundberg, J.; Leijon, M. Sonar for Environmental Monitoring: Understanding the Functionality of Active Acoustics as a Method for Monitoring Marine Renewable Energy Devices.

17. Melvin, G. D.; Cochrane, N. A. Multibeam Acoustic Detection of Fish and Water Column Targets at HighFlow Sites. Estuaries and Coasts 2014, 38, 227-240.

18. Hovem, J. M. Underwater acoustics: Propagation, devices and systems. J. Electroceramics 2007, 19 (4), 339347.

19. Mcgehee, D.; Jaffe, J. S. Three-dimensional swimming behavior of individual zooplankters: observations using the acoustical imaging system FishTV. ICES J. Mar. Sci. 1996, 53, 363-369.

20. A. D. Waite. Sonar for Practising Engineers; John Wiley \& Sons Ltd, 2002.

21. Chang, Y. C.; Hsu, S. K.; Tsai, C. H. Sidescan sonar image processing: Correcting brightness variation and patching gaps. J. Mar. Sci. Technol. 2010, 18 (6), 785-789.

22. Chu, D. Technology evolution and advances in fisheries acoustics. J. Mar. Sci. Technol. 2011, 19 (3), 245-252.

23. Ehrenberg, J.; Torkelson, T. Application of dual-beam and split-beam target tracking in fisheries acoustics. 
24. Li, F. K.; Goldstein, R. M. Studies of Multibaseline Spaceborne Interferometric Synthetic Aperture Radars. IEEE Trans. Geosci. Remote Sens. 1990, 28 (1), 88-97.

25. Traynor, J. J.; Ehrenberg Traynor, J. E.; ie Traynor, J. J.; Ehrenberg, J. E. Fish and standard-sphere targetstrength measurements obtained with a dual-beam and split-beam echo-sounding system. Cons. int. Explor. Mer 1990, 189, 325-335.

26. Popoli, R. Design and Analysis of Modern Tracking Systems (Artech House Radar Library) e-book.

27. Hastie, G. Tracking Marine Mammals Around Marine Renewable Energy Devices Using Active Sonar. 2012, pp 1-99.

28. Lundin, S.; Forslund, J.; Carpman, N.; Grabbe, M.; Yuen, K.; Apelfröjd, S.; Goude, A.; Leijon, M. The Söderfors Project : Experimental Hydrokinetic Power Station Deployment and First Results. EWTEC 2013 Proc. 2013.

29. Waters, R. Energy from Ocean Waves; 2008.

30. Leijon, M.; Boström, C.; Danielsson, O.; Gustafsson, S.; Haikonen, K.; Langhamer, O.; Strömstedt, E.; Stålberg, M.; Sundberg, J.; Svensson, O.; et al. Wave energy from the north sea: Experiences from the lysekil research site. Surv. Geophys. 2008, 29 (3), 221-240.

31. Parwal, A.; Remouit, F.; Hong, Y.; Francisco, F.; Castellucci, V.; Hai, L.; Ulvgård, L.; Li, W.; Lejerskog, E.; Baudoin, A. Wave Energy Research at Uppsala University and The Lysekil Research Site, Sweden: A Status Update. 2015, 1-10.

(C) 2016 by the authors; licensee Preprints, Basel, Switzerland. This article is an open access article distributed under the terms and conditions of the Creative Commons by Attribution (CC-BY) license (http://creativecommons.org/licenses/by/4.0/). 